\title{
PERCY JACKSON E O LADRÃO DE RAIOS: PROPOSTA DE ATIVIDADE DE MULTILETRAMENTO E DE DIALOGISMO
}

\section{PERCY JACKSON AND THE LIGHTNING THIEF: PROPOSAL OF MULTILITERACY AND DIALOGISM ACTIVITY}

\author{
Maria do Carmo Souza de Almeida ${ }^{1}$ \\ Thelma Maria Figueira Teodoro ${ }^{2}$
}

Resumo: Alguns gêneros discursivos exigem leitura verbo-visual, gerando a necessidade de multiletramento; também é preciso considerar que os discursos formam uma cadeia discursiva. Assim, objetiva-se relatar uma atividade de análise do filme "Percy Jackson e o ladrão de raios", desenvolvida no Ensino Fundamental I. Multiletramento, letramento multimidiático e dialogismo fundamentam o trabalho. Durante a exibição do filme, buscou-se relacionar as histórias de Hércules e de Perseu, além de comparar as figuras mitológicas das obras estudadas. Os resultados indicam semelhanças e diferenças entre as histórias e as personagens, uso de múltiplas linguagens e diálogo entre as histórias dos heróis.

Palavras-chave: Percy Jackson; dialogismo; multiletramento; mitologia grega.

Abstract: Some discursive genres demands verb-visual reading, creating the necessity of multiliteracy; it is also needed to consider that the discourses constitute a discursive network. Thereby the objective is to relate an analyses activity about the movie "Percy Jackson and the lightning thief", developed in the elementary school. Multiliteracy, multimidiatic literacy and dialogism substantiate the work. During the movie exhibition, it was aimed to connect Hercules and Perseus stories, besides comparing the mythological pictures of this works. The results indicate similarities and differences among the stories and the characters, use of multiples languages and dialogue between the heroes stories.

Keywords: Percy Jackson; dialogism; multiliteracy; Greek mythology.

\section{Introdução}

Este artigo tem como tema multiletramento e dialogismo. Muitos dos gêneros discursivos que circulam na contemporaneidade exigem leitura da parte escrita e das imagens que os constituem, o que implica a necessidade de atividades pautadas pelo multiletramento. Da mesma maneira, é preciso considerar, segundo Bakhtin (2011), que nenhum discurso é

\footnotetext{
${ }^{1}$ Doutora em Ciências da Comunicação, professora do Mestrado em Linguística Aplicada da Universidade de Taubaté, e-mail: alm.maria@hotmail.com

2 Mestranda em Linguística Aplicada, professora de Língua Portuguesa, Universidade de Taubaté, e-mail: thelma_teodoro@hotmail.com
} 
produzido no vazio: os discursos remetem a outros discursos, estão ligados por uma cadeia discursiva.

Assim, tem-se como objetivo relatar uma atividade de análise do filme "Percy Jackson e o ladrão de raios", desenvolvida com uma turma de quinto ano do Ensino Fundamental I, de uma escola particular, no interior do Estado de São Paulo, em 2017. Cabe ressaltar que o estudo da mitologia grega faz parte dos conteúdos abordados pelo material didático da escola em que a atividade foi desenvolvida. Além disso, esse assunto está presente em muitos filmes, desenhos animados e livros do cotidiano das crianças.

Para o desenvolvimento da atividade, foi proposto que os alunos assistissem ao filme "Percy Jackson e o ladrão de raios", buscando relacionar as histórias de dois heróis da mitologia grega: Hércules e Perseu. Além disso, procurou-se comparar as figuras mitológicas retratadas na história em quadrinhos de Hércules e na primeira versão do filme "Fúria de Titãs", de 1981, que apresenta a história de Perseu, com as que aparecem no filme "Percy Jackson e o ladrão de raios".

A atividade justifica-se porque parte de uma leitura de que os alunos gostam, estabelece vínculos entre o conteúdo a ser abordado e o conhecimento prévio dos alunos, é uma maneira de conhecer diversos modos de se abordar um mesmo assunto e possibilita diferentes experiências de leitura: texto impresso, história em quadrinhos (HQ) e filmes.

Este artigo fundamenta-se nos conceitos de letramento (SOARES, 2014), multiletramento (COPE et al., 1996; ROJO, 2012; 2013; ROJO; BARBOSA, 2015), letramento multimidiático (LEMKE, 2010) e dialogismo (BAKHTIN, 2005; 2011).

\section{Fundamentação teórica}

O conceito de multiletramento surgiu com o Grupo Nova Londres e refere-se às várias modalidades que podem constituir os gêneros discursivos: texto, imagem, áudio, gestos. Além disso, segundo Rojo e Barbosa (2015, p. 135), multiletramento envolve "[...] multiplicidade de culturas - multiculturalismo / multiplicidade de linguagens/ multissemiose e de mídias". Isso também justifica o trabalho com a mitologia grega, que faz parte da cultura ocidental e que está retratada em muitas obras artísticas.

Em um dos artigos do Grupo Nova Londres, Cope et al. defendem que é preciso pensar nas relações entre texto e imagem: 
This includes understanding and competent control of representational forms that are becoming increasingly significant in the overall comunication environment, such as visual images and their relationship to the written word - for instance, visual design in desktop publishing or the interface of visual and linguistic meaning in multimedia. (COPE et al., 1996, p. 61)

Ainda segundo Cope et al. (1996), a realização de atividades pela ótica do multiletramento focaliza dois pontos: aumentar os significados, relacionando o texto ao visual, ao áudio, e aumentar a diversidade, já que diferenças linguísticas e culturais são centrais. Isso gera necessidade de mudança no ensino, que não deve centrar-se exclusivamente na materialidade linguística dos textos.

Rojo, ao refletir sobre os textos do Grupo Nova Londres, afirma que:

A pedagogia dos multiletramentos deve partir das práticas situadas dos alunos, de que fazem parte seus interesses, repertórios e modos de vida, para, por meio da instrução aberta, criar consciência e possibilidades analíticas - uma metalinguagem - capazes de ampliar repertório e relacionar essas a outras práticas de outros contextos culturais. (ROJO, 2013, p. 18)

Isso evidencia a importância de se considerar o interesse dos alunos ao propor uma atividade, assim como propor atividades que possam desenvolver suas habilidades linguísticas e discursivas, que serão utilizadas em outros contextos, e que demonstrem práticas de uso real da linguagem.

Cabe aqui refletir sobre o conceito de letramento. Soares (2014) caracteriza letramento como fazer uso da leitura e da escrita, como apropriar-se da leitura e da escrita, envolvendo-as em práticas sociais. Devido, principalmente, às mudanças causadas pelas tecnologias, muitos gêneros discursivos não se constituem apenas da parte linguística, o que implica a necessidade de um ensino que aborde a multiplicidade de linguagens e que envolva tanto o texto quanto as imagens, os sons, os gestos. Daí a importância do multiletramento, que busca abarcar o significado do todo formado pelas informações verbo-visuais.

Costa (2013, p. 51) também ressalta a importância do trabalho com imagens: “[...] podemos compartilhar significados, crenças e valores que se tornaram coletivos [...]." Segundo a autora, atualmente há dificuldades para interpretar imagens, o que reforça a necessidade de se trabalhar a "[...] leitura de imagens como fonte de informação ou como elemento de sensibilização para a apresentação de conteúdos educativos" (COSTA, 2013, p. $55)$.

Barros (1997) caracteriza o conceito bakhtiniano de dialogismo como diálogo entre interlocutores e diálogo entre discursos. Dessa forma, o discurso é constituído pela interação dos interlocutores e pelas relações com outros discursos. O filme "Percy Jackson e o ladrão de 
raios" é um diálogo com as histórias da mitologia grega, sobretudo as histórias dos heróis Hércules e Perseu.

Bakhtin ressalta que uma obra revela sua individualidade justamente nesse diálogo com outras obras:

Essa marca da individualidade, jacente na obra, é o que cria princípios interiores específicos que a separam de outras obras a ela vinculadas no processo de comunicação discursiva de um dado campo cultural: das obras dos predecessores nas quais o autor se baseia, de outras obras da mesma corrente, das obras das correntes hostis combatidas pelo autor, etc. (BAKHTIN, 2011, p. 279)

O autor também afirma que um discurso está repleto de palavras dos outros. Assim, é necessário observar qual a orientação do discurso do autor, se está no mesmo sentido ou em sentido oposto ao discurso do outro. Além disso, todo discurso provoca respostas. Assim, os alunos, a partir de seus conhecimentos sobre o tema, respondem ao discurso veiculado em Percy Jackson e buscam argumentar sobre o que consideram adequado ou não na obra.

\section{A proposta de atividade}

Os livros e os filmes sobre a personagem Percy Jackson retratam a mitologia grega na contemporaneidade. Há um diálogo com as narrativas da mitologia grega, principalmente com as histórias dos heróis gregos. O primeiro filme da série utiliza-se, predominantemente, das histórias sobre Perseu e Hércules.

Como os alunos gostam muito dos livros e dos filmes de Percy Jackson, foi proposto um exercício de análise do filme a fim de compará-lo com as histórias de Perseu e Hércules, buscando observar como as figuras mitológicas são retratadas nas diversas leituras realizadas. Nesse sentido, Rojo (2012) entende que outros gêneros discursivos, mídias, tecnologias e linguagens devem ser abordados na escola. Dessa forma, o exercício consistiu em buscar a interdiscursividade entre as obras apresentadas.

Para iniciar a atividade, os alunos leram um texto sobre Perseu e, depois, assistiram à primeira versão do filme "Fúria de Titãs", que retrata a história desse herói. Foi possível perceber como algumas figuras mitológicas foram retratadas, como Medusa e Caronte, a influência dos deuses na vida das pessoas, a missão que o herói precisa cumprir.

Para conhecer sobre Hércules, os alunos leram "Os doze trabalhos de Hércules” em quadrinhos, uma adaptação da obra de Monteiro Lobato. Houve uma ressalva em relação à presença das personagens do Sítio do Picapau Amarelo na história, já que eles procuram 
ajudar o herói nos seus trabalhos. Foi possível conhecer a história de Hércules, observar mais uma vez a interferência dos deuses na vida das pessoas, a missão do herói e algumas figuras mitológicas, como a hidra e Cérbero.

Depois dessas leituras, foi exibido o filme "Percy Jackson e o ladrão de raios". A proposta foi fazer associações, estabelecendo interdiscursividade com as histórias dos heróis, as figuras mitológicas mostradas e os elementos da contemporaneidade no filme, pois, segundo Fiorin (2016, p. 167), “[...] todo discurso dialoga com outros discursos”. Bakhtin (2011) utiliza o exemplo de Adão para mostrar que os enunciados estão ligados a outros enunciados precedentes, que constituem uma resposta a eles; nenhum enunciado é criado no nada, não é como se fosse o primeiro enunciado.

Desse modo, foi proposta a leitura de diferentes gêneros discursivos - texto informativo, quadrinhos, filme -, bem como o trabalho com multiletramento, já que, além do texto impresso, houve o trabalho com imagens dos filmes e da história em quadrinhos. Multiletramento envolve uma leitura que vai além da palavra, uma leitura que envolve as imagens, os sons, a diagramação, pois os textos, assim como a história em quadrinhos (HQ), por exemplo, são compostos por muitas linguagens, “[...] que exigem capacidades e práticas de compreensão e produção de cada uma delas (multiletramentos) para fazer significar" (ROJO, 2012, p. 19).

Para ilustrar a atividade, seguem as imagens de Medusa trazidas pelos filmes:

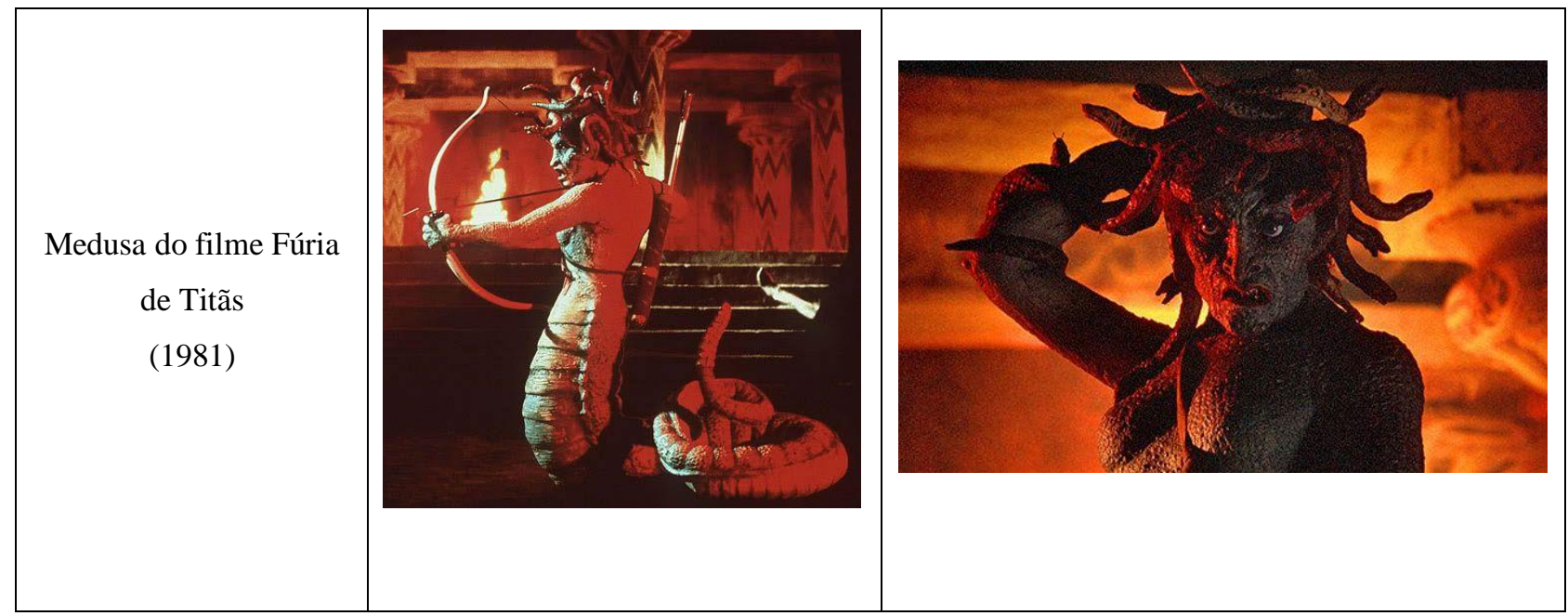




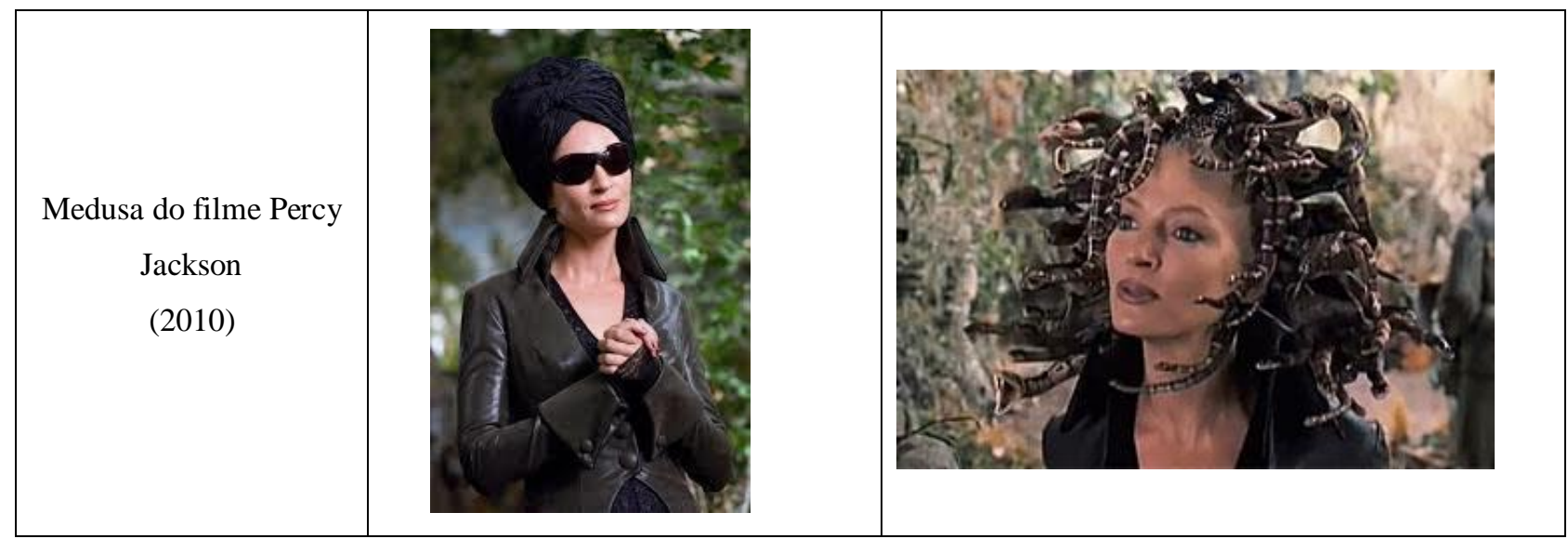

Embora os recursos tecnológicos e os efeitos visuais já estejam mais aprimorados em Percy Jackson, a primeira consideração feita pelos alunos é a de que a Medusa, nesse filme, não é um monstro. Ela é retratada como uma mulher bonita, usa roupas, óculos escuros e batom, pinta as unhas. Já a Medusa de "Fúria de Titãs" é um monstro e luta contra seus adversários. Além disso, é retratada como parte mulher, parte serpente - a de Percy Jackson é uma mulher somente - e tem pele escamosa. Essa comparação permite refletir sobre a forma como um mesmo fato pode ser retratado, perceber que "[...] ler uma imagem é identificar um tema e perceber como ele se traduz, através de signos visuais, numa narrativa" (COSTA, 2013, p. 63, grifo do autor).

Para Bakhtin (2005), é preciso observar o ângulo dialógico de uma obra, que não se restringe ao campo linguístico. Assim, é possível perceber como a Medusa foi retratada em 1981 e em 2010. Apesar de a primeira imagem parecer uma montagem no filme, devido aos recursos disponíveis, ela remete mais à ideia de uma mulher castigada que virou um monstro do que a segunda, apesar de toda a tecnologia. É como se a segunda Medusa fosse uma mulher contemporânea com cabelos de cobra. Os alunos ainda observaram o diálogo existente entre Perseu e Percy Jackson, pois ambos precisam enfrentar a Medusa para salvar alguém, ação que se caracteriza como uma das missões dos heróis gregos. Assim, ao observar as diferentes formas de retratar a Medusa, é possível demonstrar “[...] as ligações e as redes de interdependência" que se estabelecem entre os discursos (LEMKE, 2010, p. 459).

Outra distinção observada consiste no uso de armas pela Medusa de "Fúria de Titãs". Ela luta contra Perseu, tenta se defender arremessando flechas no herói. Guiado pelo reflexo do escudo, Perseu consegue aproximar-se e cortar a cabeça de Medusa. Em Percy Jackson, o monstro não tem armas; ela o segura e tenta convencê-lo a abrir os olhos. O herói recebe a 
ajuda dos amigos para se esquivar da Medusa e, ao ver o reflexo do monstro no celular, decapita-a.

Para Lemke (2010), o ensino precisa abordar a combinação entre texto escrito/impresso e imagens visuais, pois há significados multiplicativos; é necessário oferecer o letramento de várias mídias, com diferentes combinações de significados, multiplicando os letramentos. Isso se torna necessário, pois há vários gêneros discursivos que combinam linguagem verbal e linguagem não verbal. Esses gêneros fazem parte do cotidiano dos alunos e compreendê-los faz parte da responsabilidade de formação da escola. A escola precisa estar atenta às necessidades dos alunos, bem como oferecer condições para que eles possam apropriar-se do conhecimento e utilizá-lo adequadamente em seu cotidiano.

Um dos gêneros discursivos que combina linguagem verbal e não verbal é a HQ. Na atividade proposta, os alunos puderam comparar e relacionar cenas do filme com a história de Hércules em quadrinhos. As figuras abaixo ilustram como a hidra foi retratada:

\begin{tabular}{|l|l|l|}
\hline \\
Hidra da HQ do \\
Hércules \\
(2012, p. 31)
\end{tabular}


Enfrentar a hidra era parte dos trabalhos de Hércules. Percy Jackson precisa enfrentála para conseguir salvar sua mãe. Tanto na HQ quanto no filme, a hidra tem dez cabeças. Os alunos puderam observar que, na $\mathrm{HQ}$, ela se parece com um dragão, mas não cospe fogo; enquanto em Percy Jackson, ela se parece com um monstro e cospe fogo. As cores para retratar a hidra também são bem distintas: uma é verde e amarela, a outra, cinza. A hidra de Hércules parece não amedrontar o herói, enquanto a de Percy Jackson intimida mais o herói. Assim, os alunos percebem o ângulo dialógico (BAKHTIN, 2005) das obras em relação a essa figura mitológica: a hidra da HQ tem uma representação mais infantil, de acordo com o público alvo a quem se destina o livro - para crianças. A hidra do filme precisa parecer mais realista, para que o espectador se assuste e tenha a impressão de que é um monstro verdadeiro.

Costa (2013, p. 54) defende que as atividades pedagógicas com imagem devem utilizar tanto obras consagradas e reconhecidas como "[...] imagens que cobrem os muros das grandes cidades ou as embalagens dos produtos expostos no supermercado". É preciso também valorizar as imagens que estão presentes no cotidiano dos alunos.

Além disso, os enunciados geraram atitudes responsivas. Segundo Bakhtin (2011, p. 271), o ouvinte (o interlocutor) não é passivo, não fica só recebendo as informações: “[...] o ouvinte, ao perceber e compreender o significado (linguístico) do discurso, ocupa simultaneamente em relação a ele uma ativa posição responsiva: concorda ou discorda [...]", completa-o e pode usá-lo. Toda compreensão carrega respostas (mesmo que não sejam em voz alta). Aqui cabe uma observação de Rojo (2013): Bakhtin e o Círculo trataram do texto escrito, impresso. Assim, além do que foi apontado pelos estudos do Círculo, também é necessário considerar, atualmente, as mídias e as tecnologias nas práticas escolares, pois o texto manifesta-se nos aspectos verbo-visuais. Na atividade relatada, os alunos puderam responder ao que assistiram, demonstrar sua concordância/discordância com o que foi retratado em "Percy Jackson e o ladrão de raios", assim como estabelecer relações entre as obras - o que era mostrado em Percy Jackson que remetia à história de Hércules ou de Perseu - e as formas como as figuras mitológicas foram representadas.

Para Costa (2013), diferentes leituras de uma imagem são possíveis. Dessa forma, pode-se considerar que nem todas as respostas e as observações precisam ser iguais, pois, segundo Bakhtin (2011), o sentido de uma obra completa-se com as experiências do leitor. Costa (2013, p. 63) afirma que

A leitura da imagem não é um mergulho no desconhecido, pois o autor organizou sua obra de maneira a que ela seja lida pelo observador: ele criou um recorte; 


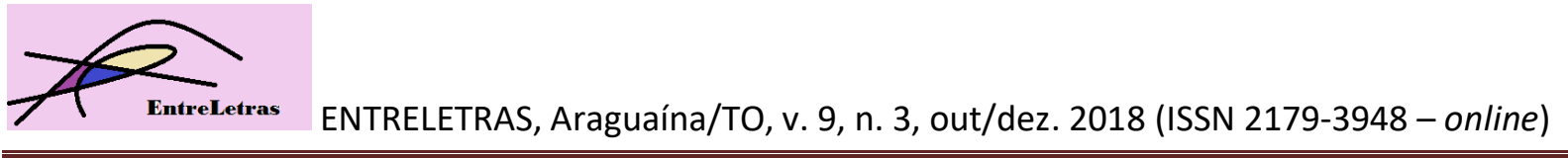

hierarquizou as figuras; com a luz colocou certos aspectos em evidência, encobrindo outros; aproximou certos elementos do público, deixando outros ao fundo. Ele orienta o observador por meio de gestos emprestados às figuras e de linhas e movimentos pelos quais nosso olhar se esgueira. (COSTA, 2013, p. 63)

Ao abordar o trabalho com imagem, Bunzen, Mendonça et al. (2013) afirmam que ela não deve ser considerada como uma forma de ilustração da escrita. Segundo os autores, é no entrelaçamento entre texto e imagem que se produz o sentido de uma obra. Assim, refletir com os alunos sobre as diferenças entre as duas formas de representação da hidra e o porquê dessas diferenças corresponde ao oferecimento de uma prática de letramento de imagens.

Dessa maneira, torna-se possível comparar também como a figura de Caronte, o barqueiro do submundo, e o rio Estige foram retratados nas três obras:

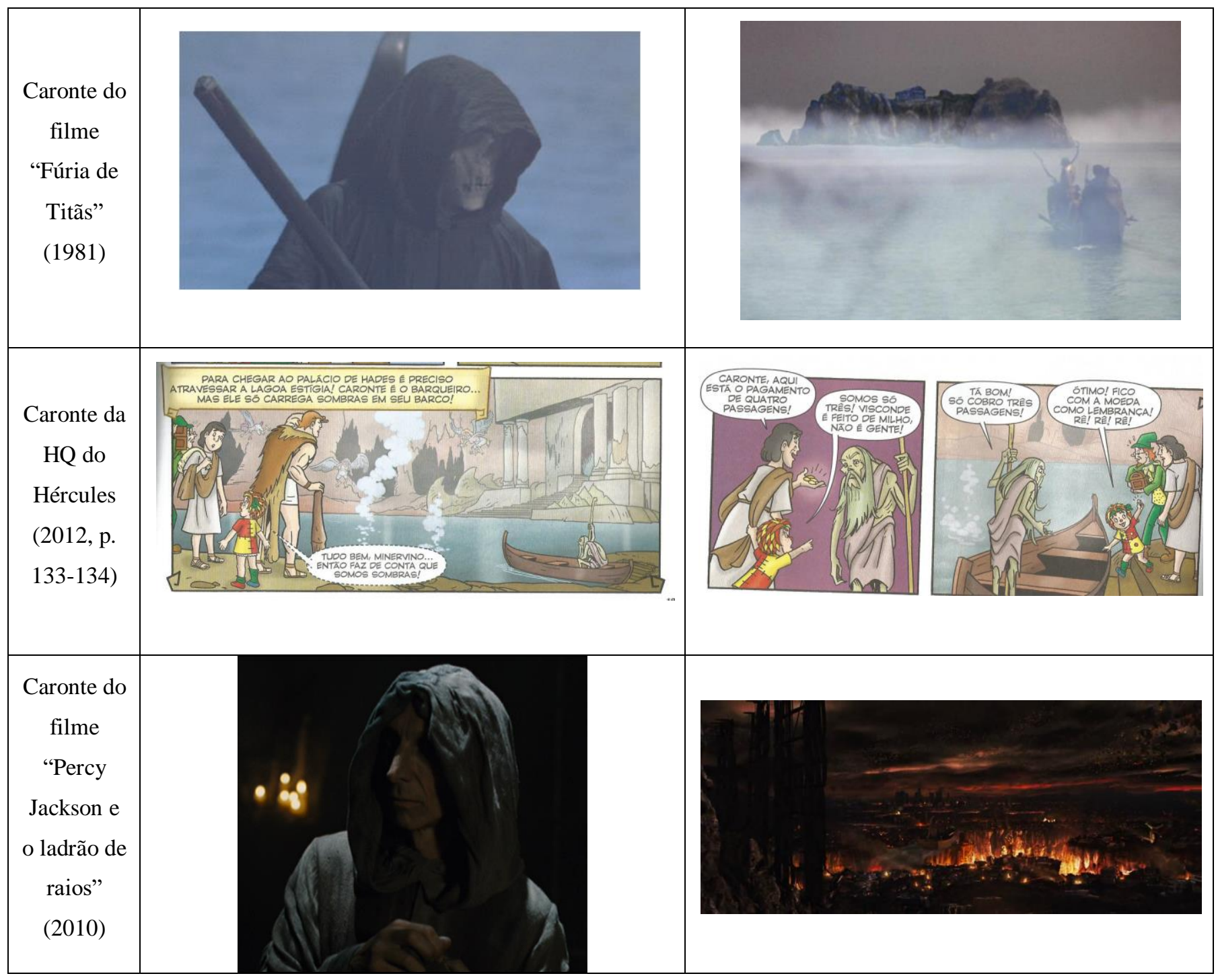


De acordo com as obras, os três heróis precisam atravessar o rio Estige e, assim, precisam se encontrar com Caronte: Perseu atravessa o rio para chegar até a caverna da Medusa, Hércules vai até o submundo para pegar Cérbero, o cão de três cabeças de Hades, e Percy Jackson vai até o submundo para resgatar sua mãe, que foi aprisionada por Hades.

No filme "Fúria de Titãs", Caronte é uma caveira que veste uma roupa com capuz. O rio Estige está encoberto por uma névoa; do outro lado do rio, está a caverna da Medusa. A figura de Caronte, na HQ de Hércules, tem aspecto humano, parece alguém de muita idade, magro, com barba comprida. O rio Estige também está encoberto por uma névoa. Em Percy Jackson, Caronte também apresenta aspecto humano e está com uma roupa com capuz. As cores para retratar Caronte são escuras. Caronte leva Percy Jackson sobre o rio, entretanto o rio não aparece e são mostradas partes do submundo. Também há uso de cores escuras para a cena da travessia. Nas três obras Caronte aparece segurando o remo do barco.

Analisar as distintas formas de representação de Caronte, bem como as das demais imagens, oferece, segundo Lemke (2010, p. 462) um "[...] significado multiplicador, porque as opções de significados de cada mídia multiplicam-se entre si em uma explosão combinatória." Desse modo, os sentidos dos gêneros discursivos abordados na atividade não são produzidos de maneira isolada, mas relacionando texto e imagem e os discursos sobre mitologia grega, evidenciando as ligações entre as histórias de Hércules, Perseu e Percy Jackson.

Rojo (2012, p. 13) afirma que o conceito de multiletramento traz "multiplicidade semiótica de constituição dos textos por meio dos quais ela se informa e se comunica." A compreensão do texto passa, portanto, pela linguagem verbo-visual, pois é na combinação entre a parte linguística e a parte imagética que os filmes e a HQ ganham sentido. Atualmente, é imprescindível considerar a verbo-visualidade na constituição dos textos, por isso atividades pautadas pelo multiletramento precisam fazer parte do cotidiano escolar. Além disso, Rojo (2013, p. 18) ressalta que novos gêneros discursivos devem ser introduzidos na escola, para que sejam abordadas "[...] outras e novas mídias, tecnologias, línguas, variedades, linguagens."

A atividade relatada procurou oferecer "diferentes estéticas" (ROJO, 2012, 28), diferentes formas de se retratar um mesmo assunto. Foi uma proposta que buscou, de acordo com Rojo (2013), uma prática linguístico-discursiva adequada à contemporaneidade, marcada pela utilização dos recursos verbo-visuais. Bunzen, Mendonça et al. enfatizam que: 
Assumir o letramento como propósito do ensino no contexto dos ciclos escolares significa adotar uma concepção social da escrita, em que o conteúdo deixa de ser o elemento estruturante do currículo para dar lugar às práticas sociais, dentro das quais se buscarão os textos realmente significativos para o aluno, sua comunidade e suas vivências, locais ou não. (BUNZEN et al., 2013, p. 72)

\section{Considerações finais}

Na contemporaneidade, é necessário o uso de múltiplas linguagens para compreender muitos dos gêneros discursivos que circulam socialmente. Auxiliar o aluno na atividade de compreensão, que envolve significados também múltiplos, faz parte das tarefas da escola. Assim, esta proposta de atividade vai do texto impresso à imagem fílmica, buscando entrelaçar as histórias dos heróis gregos à história de Percy Jackson. Procurou-se desenvolver, em uma atividade que considerasse os interesses dos alunos, no caso, os livros e os filmes sobre Percy Jackson, leituras diferenciadas de diferentes linguagens.

Para Lemke (2010, p. 463), as atividades de letramento multimidiático devem basearse em: "Apresentação (criar ou descrever o mundo), Orientação (tomar partido em relação à Apresentação ou a suas audiências) e Organização (ligar as partes ao todo)". Assim, os quadrinhos ajudaram a demonstrar as figuras mitológicas e a conhecer a história de Hércules, e as leituras sobre Perseu ajudaram a perceber a forma distinta de retratar a Medusa, por exemplo. Então, os alunos destacaram semelhanças e diferenças entre as histórias e as personagens, e posicionaram-se sobre o que consideravam adequado ou não em Percy Jackson e o ladrão de raios.

Muitos outros aspectos podem ser considerados nesta proposta de atividade que envolve multiletramento e dialogismo. Buscou-se aqui retratar um deles e um caminho a ser trabalhado.

Faz-se necessário ainda considerar que letramento caracteriza-se como o “[...] resultado da ação de ensinar e aprender as práticas sociais de leitura e escrita", como o "[...] estado ou condição que adquire um grupo social ou indivíduo como consequência de ter-se apropriado da escrita e de suas práticas sociais" (SOARES, 2014, p. 39, grifo do autor). Dessa forma, ao realizar as atividades de leitura propostas, os alunos puderam se apropriar do que foi exposto para fazerem uso desse conteúdo ao analisar o filme.

Rojo (2013, p. 17) alerta “[...] que as escolas precisam ensinar aos alunos novas formas de competências nesses tempos. [...] No campo específico dos multiletramentos, isso implica negociar uma crescente variedade de linguagens e discursos." Para a autora, utilizar 
práticas de multiletramento ocasiona interagir com outras linguagens para produzir sentido em meio a tantos discursos que se apresentam no cotidiano.

Vale ressaltar ainda, de acordo com Lemke (2010), que os letramentos multimidiáticos devem ser ensinados desde o princípio da vida escolar, o que corrobora a importância de práticas como esta durante o Ensino Fundamental I, que pode ser considerado a base da formação escolar. O autor também destaca que atividades de letramento auxiliam o aluno no discernimento e a atribuir significado ao mundo.

Desse modo, a atividade relatada buscou trabalhar os conceitos de multiletramento e dialogismo, para que o conteúdo abordado pudesse gerar reflexão e fosse significativo, para que fosse, enfim, uma prática de uso real da linguagem. Por intermédio dessa atividade, buscou-se refletir sobre a maneira de representação da mitologia grega na contemporaneidade, as diversas linguagens que formam uma obra - e, para entendê-la, é necessário unir texto e imagem -, a interdiscursividade entre as obras apresentadas, bem como apresentar uma atitude responsiva diante do filme "Percy Jackson e o ladrão de raios".

Práticas assim são necessárias, segundo Cope et al. (1996), pois uma atividade deve oferecer habilidades e conhecimento aos estudantes, para que utilizem o que foi aprendido em seu cotidiano e atinjam seus propósitos. Da mesma forma, é preciso atentar que leitura e escrita não se limitam à escola: "lemos e escrevemos para agir no (e sobre o) mundo" (BUNZEN, MENDONÇA et al., 2013, p. 74). Segundo os autores, as práticas de letramento é que oferecerão aos alunos meios para utilizarem a leitura e a escrita como uma forma de produzir sentido. A partir das atividades escolares, as práticas de leitura e escrita farão sentido em outras práticas, em outros contextos.

\section{Referências}

BAKHTIN, M. M. Estética da criação verbal. 6. ed. Trad. Paulo Bezerra. São Paulo: WMF Martins Fontes, 2011.

Problemas da poética de Dostoiévski. 3. ed. Trad. Paulo Bezerra. Rio de Janeiro: Forense Universitária, 2005.

BARROS, D. L. P. de. Contribuições de Bakhtin às teorias do discurso. In: BRAIT, B. (Org.). Bakhtin, dialogismo e construção de sentido. Campinas: Editora da UNICAMP, 1997.

BUNZEN, C.; MENDONÇA, M. et al. Múltiplas linguagens para o ensino médio. São Paulo: Parábola, 2013. 
COPE, B. et al. A pedagogy of multiliteracies: Designing social futures. Harvard Educational Review; Spring 1996; 66, 1; Research Library, p. 60-91. Disponível em:

$<$ http://newarcproject.pbworks.com/f/Pedagogy+of+Multiliteracies_New+London+Group.pdf $>$. Acesso em 23 de julho de 2018.

COSTA, C. As imagens clássicas. In: COSTA, C. Educação, imagem e mídias. 2. ed. São Paulo: Cortez, 2013. Coleção aprender e ensinar com textos, v. 12.

FIORIN, J. L. Interdiscursividade e intertextualidade. In: BRAIT, B. (Org.). Bakhtin: outros conceitos-chave. 2. ed. São Paulo: Contexto, 2016.

LEMKE, J. Letramento metamidiático: transformando significados e mídias. Trabalhos em Linguística Aplicada, Campinas, 49, p. 455-479, jul./dez. 2010.

ORTEGA, D. Os doze trabalhos de Hércules (adaptado da obra de Monteiro Lobato). São Paulo: Globo, 2012. Coleção Monteiro Lobato em quadrinhos.

ROJO, R. H. R. Diversidade cultural na escola. In: ROJO, R. H. R.; MOURA, E. (Org.). Multiletramentos na escola. São Paulo: Parábola, 2012.

Gêneros discursivos do Círculo de Bakhtin e multiletramentos. In: ROJO, R. H. R. (Org.).Escol@ conectad@: os multiletramentos e as TICs. São Paulo: Parábola, 2013.

ROJO, R. H. R.; BARBOSA, J. P. Hipermodernidade, multiletramentos e gêneros discursivos. São Paulo: Parábola, 2015.

SOARES, Magda. Letramento: um tema em três gêneros. Belo Horizonte: Autêntica, 2014. 